\title{
Periprosthetic infection is the major indication for TKA revision - experiences from a university referral arthroplasty center
}

\author{
S. P. Boelch, A. Jakuscheit, S. Doerries, L. Fraissler, M. Hoberg, J. Arnholdt ${ }^{* \dagger}$ (i) and M. Rudert ${ }^{\dagger}$
}

\begin{abstract}
Background: We hypothesized, that periprosthetic joint infection (PJI) accounts for the major proportion of first (primary) and repeated (secondary) Total Knee Arthroplasty revisions at our university referral arthroplasty center.

Methods: One thousand one hundred forty-three revisions, performed between 2008 and 2016 were grouped into primary (55\%) and secondary (45\%) revisions. The rate of revision indications was calculated and indications were categorized by time after index operation. The odds ratios of the indications for primary versus secondary revision were calculated.

Results: In the primary revision group PJI accounted for 22.3\%, instability for $20.0 \%$, aseptic loosening for $14.9 \%$ and retropatellar arthrosis for $14.2 \%$. PJ (25.6\%) was the most common indication up to 1 year after implantation, retropatellar arthrosis (26.8\%) 1-3 years and aseptic loosening (25.6\%) more than 3 years after implantation. In the secondary revision group PJI accounted for 39.7\%, aseptic loosening for $16.2 \%$ and instability for $13.2 \%$. PJ was the most common indication at any time of revision with $43.8 \%$ up to one, 35.4\% 1-3 years and 39.4\% more the 3 years after index operation.

The odds ratios in repeated revision were 2.32 times higher $(p=0.000)$ for PJI. For instability and retropatellar arthrosis the odds ratios were 0.60 times $(p=0.006)$ and 0.22 times $(p=0.000)$ lower.

Conclusions: $\mathrm{PJl}$ is the most common indication for secondary TKA revision and within one year after primary TKA. Aseptical failures such as instability, retropatellar arthrosis and aseptical loosening are the predominant reasons for revision more than one year after primary TKA.
\end{abstract}

Keywords: Knee arthroplasty, Revision, Periprosthetic infection, Failure

\section{Background}

Total knee arthroplasty (TKA) is the treatment of choice for symptomatic arthrosis. Patient satisfaction with TKA has improved from $81.2 \%$ between the years 1990 and 1999 to $85 \%$ between the years 2000 and 2012 [1], but still absolute revision numbers are increasing. Although revision rates after TKA remain constantly low, data from the Nationwide Inpatient Sample (NIS) showed an increase of TKA revisions of 39\% from 48,260 in 2006 to

\footnotetext{
* Correspondence: j-arnholdt.klh@uni-wuerzburg.de

${ }^{\dagger}$ J. Arnholdt and M. Rudert contributed equally to this work.

Department of Orthopaedic Surgery, Julius-Maximilians University Wuerzburg,

Koenig-Ludwig-Haus, 11 Brettreichstrasse, 97074 Wuerzburg, Germany
}

67,534 in 2010 in the US [2]. In the first annual report of the German joint registry an increase of $144 \%$ was demonstrated from 7238 in 2004 to 17,658 in 2014 [3]. Recent clinical studies focusing solely on primary revisions found aseptic reasons such as instability with 19 and $22 \%$, and aseptic loosening with 31 and $22 \%$ the two most common indications $[4,5]$. The analysis of the Swedish, Norwegian, Finnish, Danish, Australian and the New Zealand registry by Sadoghi et al. stated, that the two most common reasons for TKA revisions between 1979 and 2009 were aseptic and septic loosening with $29.8 \%$ and $14.8 \%$, respectively [6]. In contrast to aseptical revisions, management of periprosthetic joint infections

(c) The Author(s). 2018 Open Access This article is distributed under the terms of the Creative Commons Attribution 4.0 International License (http://creativecommons.org/licenses/by/4.0/), which permits unrestricted use, distribution, and reproduction in any medium, provided you give appropriate credit to the original author(s) and the source, provide a link to the Creative Commons license, and indicate if changes were made. The Creative Commons Public Domain Dedication waiver (http://creativecommons.org/publicdomain/zero/1.0/) applies to the data made available in this article, unless otherwise stated. 
(PJI) necessitates an interdisciplinary setting and special care [7]. This peculiarity of PJI management leads to a pooling of the affected patients at specialized referral arthroplasty centers, as the study institution is.

That is why we hypothesized, that PJI accounts for the major proportion of primary and secondary revisions at our institution. Additionally, we hypothesized that, in contrast to primary revision, the frequency of PJI is not related to time of revision for secondary revision.

\section{Methods}

\section{Study design}

This observational study was performed at the Department of Orthopaedic Surgery, University of Wuerzburg in Germany. Approval was waived by the University's ethics committee (approval number 20180613 01).

\section{Setting}

In August 2016, our department's electronic data was scanned for all TKA revisions, that were performed since the introduction of our electronic database in December 2008. Only procedures involving an arthrotomy were considered a revision. The failure mechanism described by the operating surgeon as decisive for revision strategy was defined as indication for revision. Indications were categorized into polyethylene (PE)-wear, aseptic loosening, PJI, instability, periprosthetic fracture, malalignment, extensor mechanism deficiency, arthrofibrosis, retropatellar arthrosis and other.

The authors acknowledge that diagnostic algorithms of the painful TKA are discussed controversial and are still under investigation [8-12]. Thus, the predominant indications for revision are described in brief: PE-wear was diagnosed by radiographs showing osteolysis or progressive joint space narrowing under load, by intraoperatively macroscopic visible wear and by histopathologic evaluation of intraoperative samples according to Krenn and Morawietz [13].

PJI was evaluated in accordance with the guidelines of the Infection Disease Society of America [14]. Two stage exchanges were regarded as one event.

Instability was assessed based on the patient's history for example with swelling and giving way events. Additionally, coronal and sagittal instability was evaluated by clinical examination and on radiographs as described elsewhere [10]. In cases of concomitant loosening or PE-wear, these were the primary diagnosis.

Arthrofibrosis was diagnosed by painful restriction of range of motion that was refractory to intensified physiotherapy, without any other underlying reason.

For alignment evaluation, we routinely used the alignment parameters based on The Knee Society Total Knee Arthroplasty Roentgenographic Evaluation and Scoring
System $[15,16]$. CT-scans were added on the bases of clinical and radiologic work up.

\section{Patients}

One thousand one hundred forty-three revisions were identified. Revisions were performed in $36.4 \%$ in male and in $63.6 \%$ in female patients with a mean age of 67.9 years (21-93). First revisions after the primary TKA (index operation) were assigned to the primary revision group (55.0\%). In case of any previous revision, which was not the primary implantation, this was regarded the index operation for the secondary revision group (45.0\%).

The mean duration from index operation to revision was 42.1 months $(0-279) .55 .5 \%$ of the primary revision cases and $38.9 \%$ of the secondary revision cases were transferred to our institution for further operation.

To support a unification of the time to failure categorization we subdivided the time from index operation to revision in accordance with the recently published study by Thiele et al. into 1 year, $1-3$ years and more than 3 years [5].

\section{Statistics}

Means were compared with the $\mathrm{t}$-Test. Odds ratios for the indications were calculated depending on primary or secondary revision and tested for significant differences with the Pearson chi square test. Statistics were performed with SPSS 24 (SPSS Inc. Chicago, USA).

\section{Results}

\section{Primary revision group}

In the primary revision group the major proportion (71.4\%) of revisions was due to the four indications: PJI (22.3\%), instability (20.0\%), aseptic loosening (14.9\%) and retropatellar arthrosis (14.2\%) (Fig. 1).

26.7\% were revised within 1 year after the implantation. In this group, the most common indication was PJI (25.6\%), followed by instability (19.0\%) and retropatellar arthrosis (13.1\%). 31.5\% of TKAs failed 1-3 years after implantation. Of these $26.8 \%$ were due to retropatellar arthrosis, $24.7 \%$ due to instability and $20.7 \%$ due to PJI. $41.0 \%$ were revised more than three after index operation. $25.6 \%$ of these revisions were because of aseptic loosening, $20.2 \%$ because of PJI, $18.2 \%$ because of PE-wear and $17.4 \%$ because of instability. The complete distributions are shown in Fig. 2.

\section{Secondary revision group}

In the secondary revision group $68.1 \%$ of the revisions were due to three indications: PJI (39.7\%), aseptic loosening (16.2\%) and instability (13.2\%) (Fig. 3).

The most common indication of the $37.7 \%$ revisions within 1 year from index operation was PJI (43.8\%), followed by aseptic loosening (13.9\%) and instability 


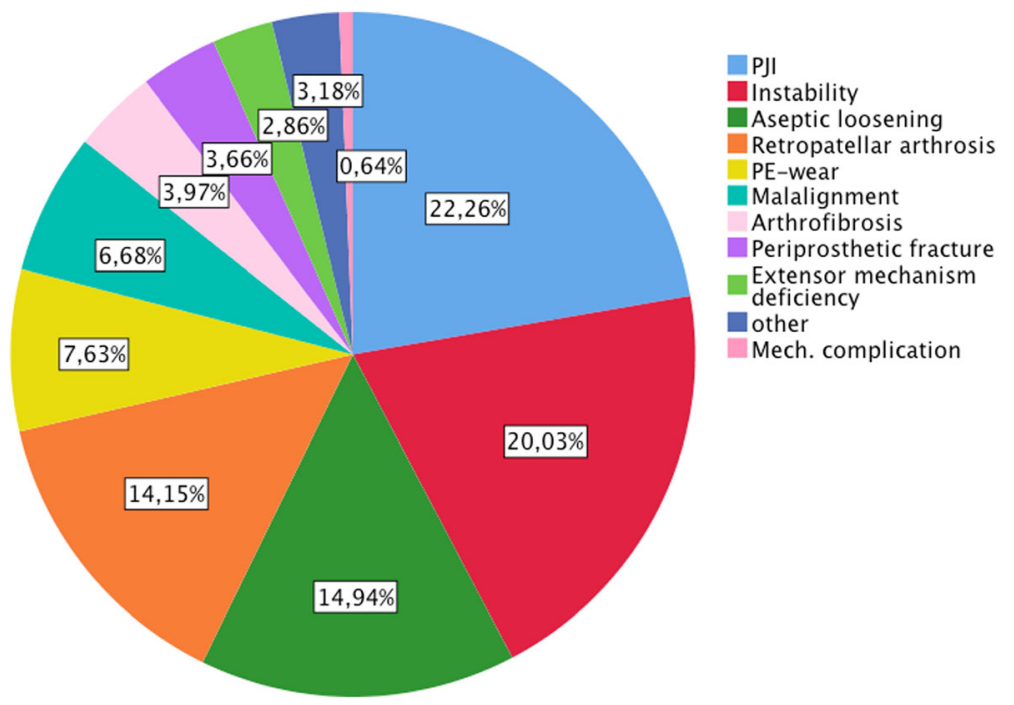

Fig. 1 Indications for primary revision

(11.3\%). A comparable distribution was found for the $36.8 \%$ revisions between 1 and 3 years with 35.4, 15.9 and $14.8 \%$ and for the remaining $25.5 \%$ revision after more than 3 years with $39.4,21.3$ and $12.6 \%$. The detailed distributions are depicted in Fig. 4.

\section{Comparison of primary and secondary revisions}

The odds of being revised for PJI were 2.5 times higher $(p<0.000)$ for secondary revisions. However, the odds of being revised for instability or retropatellar arthrosis were significantly lower for secondary revisions (Table 1 ).

The mean duration to revision because of PJI and because of aseptic loosening was significantly $(p=0.000)$ shorter in the secondary revision group (Table 2 ).

\section{Discussion}

We found PJI to be the most common indication for both, primary and secondary TKA revision at a university referral arthroplasty center. This result is in accordance with the numbers published from the NIS for knee arthroplasty revisions, without discriminating primary from secondary revisions [17]. The odds ratio from the current study demonstrates, that PJI is particularly the major revision indication for secondary revisions. The few other available studies on reasons for re-revisions report comparable rates of PJI as revision indication for secondary revisions. Suarez et al. had a re-revision rate of $46 \%$ for PJI in their 68 knees that underwent secondary revision [18]. Mortazavi et al. described this rate to be $44 \%$ in their study of 102 knees [19]. However, in contrast to previous publications, we found PJI to be the

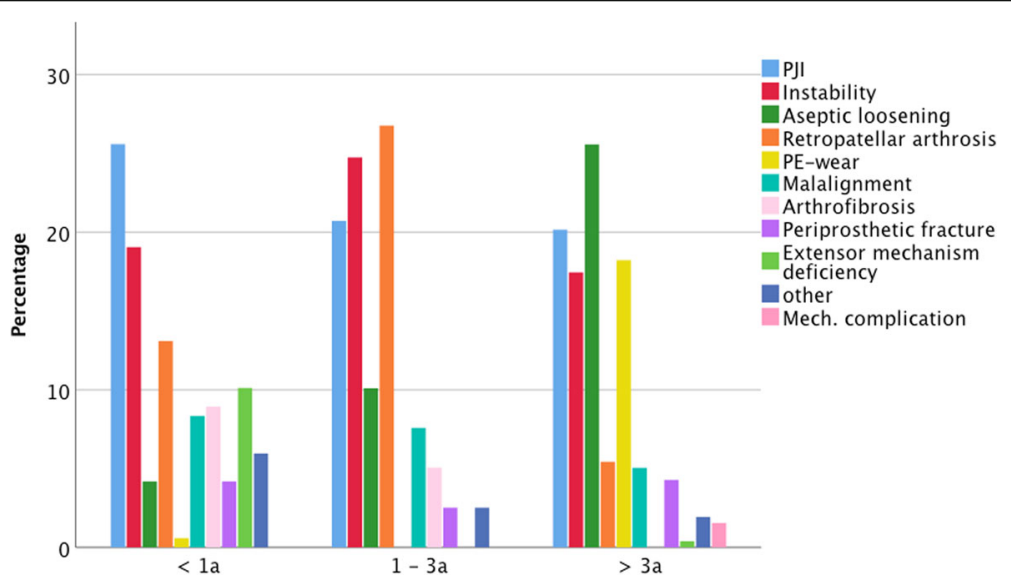

Fig. 2 Distributions of indications for primary revision 


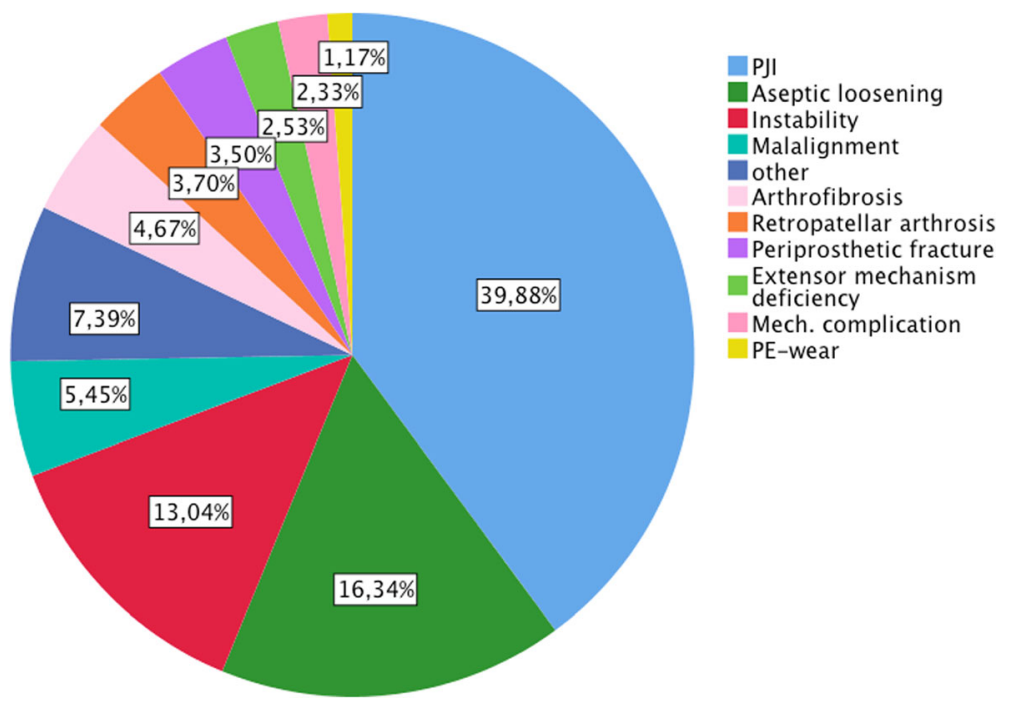

Fig. 3 Indications for secondary revision

most common indication for primary revisions, too. In the study of 358 primary revisions by Thiele et al. PJI was the fourth most common indication with a proportion of $15 \%$ [5]. In their study, revisions with component retention were excluded. However, debridement and irrigation with retention of the fixed components is a warranted treatment regime for early postoperative or acute periprosthetic infection $[14,20]$. These cases are included in our study and are represented by the finding, that PJI was predominantly found for primary revision within 1 year after index operation. Schroer et al. described PJI the third most common reason with a proportion of $16.2 \%$ of 844 patients treated at six different institutions [4]. However, we present monocentric results based on standardized diagnostic algorithms.

In contrast to PJI, retropatellar arthrosis and instability are specific issues of primary TKA. In accordance with our results, instability is consistently reported a major failure mechanism after primary TKA $[4,5,21]$. However, retropatellar arthrosis was the most common revision reason 1-3 years after the implantation, what reflects the development of clinically relevant and radiographically obvious retropatellar wear.

This study has limitations because of its retrospective design and the complexity of TKA revision.

If the treatment of PJI failed and the patient was readmitted, the following revision was considered a new

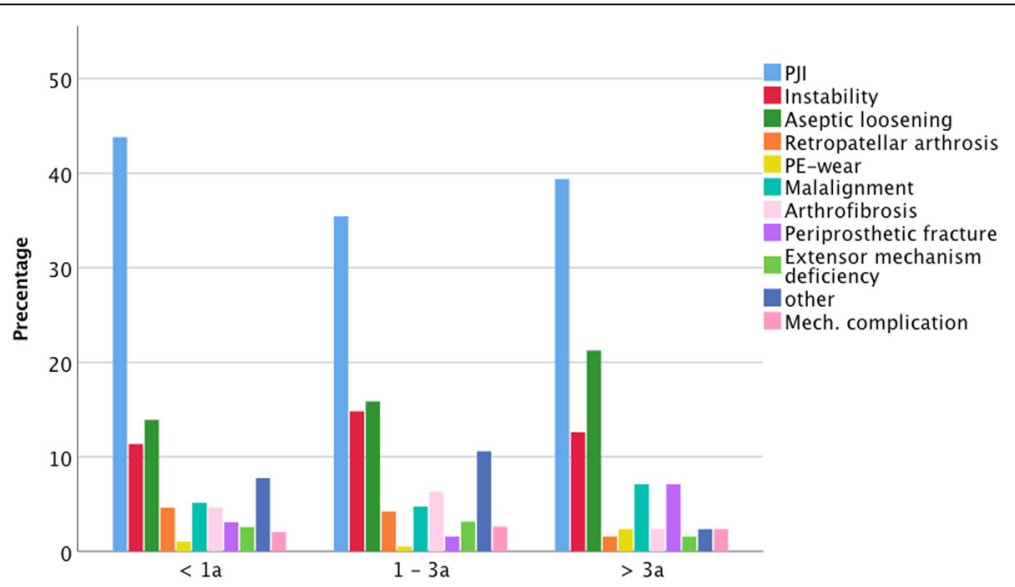

Fig. 4 Distributions of indications for secondary revision 
Table 1 Odds ratios depending on secondary revision/primary revision of the 4 major indications for revision

\begin{tabular}{lll}
\hline Indication for revision & Odds ratio $(95 \% \mathrm{Cl})$ & $\begin{array}{l}\text { Pearson chi square } \\
\text { test } \mathrm{p}\end{array}$ \\
\hline PJI & $2.32(1.79-3.00)$ & 0.000 \\
Instability & $0.60(0.43-0.83)$ & 0.002 \\
Aseptic loosening & $1.11(0.81-1.53)$ & 0.517 \\
Retropat. arthrosis & $0.22(0.13-0.36)$ & 0.000 \\
\hline
\end{tabular}

case. In this study with 345 primary and secondary revisions, about $10 \%$ were repeatedly revised for reinfection. Thus, the proportion of PJI might be biased by patient specific characteristics.

Further, we did not investigate the proportion of resurfaced patellae before revision. These cases were not excluded from the analysis because the proportion of failures due to patellar arthrosis is clinically relevant and the discussion of the best treatment is still going on [22]. The significantly higher proportion of retropatellar arthrosis in the primary revision group is highly likely to be owed to the fact, that the secondary revisions had a higher rate of resurfaced patella before re-revision.

The 14th NJR annual reported aseptical failure mechanisms the most frequent reasons for primary revision [23]. The current monocenter study at a university referral arthroplasty center found PJI the leading failure mechanism irrespectively whether after primary or revised TKA. This discrepancy is owed the pooling of patients. It displays the enormous challenge of referral arthroplasty centers to especially ensure the management of PJI as a potentially life threating TKA failure with the danger of devastating sequela.

\section{Conclusion}

PJI is the most common indication for secondary TKA revision and within one year after primary TKA. Aseptical failures such as instability, retropatellar arthrosis and aseptical loosening are the predominant reasons for revision more than one year after primary TKA.

Table 2 Mean duration and range from index operation to revision in months

\begin{tabular}{llll}
\hline Indication for revision & $\begin{array}{l}\text { Duration to } \\
\text { primary revision } \\
\text { in months (range) }\end{array}$ & $\begin{array}{l}\text { Duration to } \\
\text { secondary revision } \\
\text { in months (range) }\end{array}$ & $p$ \\
\hline PJI & $49.00(0-279)$ & $28.11(0-198)$ & 0.000 \\
Instability & $37.67(2-226)$ & $31.48(4-153)$ & 0.301 \\
Aseptic loosening & $94.68(5-242)$ & $31.05(1-163)$ & 0.000 \\
Retropatellar arthrosis & $24.54(3-106)$ & $19.53(3-58)$ & 0.677 \\
\hline
\end{tabular}

\section{Abbreviations}

CT: Computed tomography; NIS: Nationwide Inpatient Sample; PE: Polyethylene; PJI: Periprosthetic joint infection; TKA: Total knee arthroplasty

\author{
Acknowledgments \\ None. \\ Funding \\ This publication was supported by the Open Access Publication Fund of the \\ University of Wuerzburg. The study was funded by internal sources of the \\ Department of Orthopaedic Surgery, Koenig-Ludwig-Haus. The funding body \\ had no role in the design of the study and collection, analysis, and interpretation \\ of data and in writing the manuscript.
}

\section{Availability of data and materials}

The datasets used and analyzed during the current study are available from the corresponding author on reasonable request.

\section{Authors' contributions}

SB were responsible for the design and coordination of this study and wrote the manuscript. AJ and SD were responsible for the acquisition of data, interpretation of data and performed the statistical analysis. LF made substantial contributions to conception and design of the study and to analysis and interpretation of data. MH and JA supervised the project and helped to draft the manuscript. MR and JA revised the manuscript and gave final approval for publication. MR made substantial contributions to conception and design of the study. All authors read and approved the final manuscript.

\section{Ethics approval and consent to participate}

This observational study was performed at the Department of Orthopaedic Surgery, University of Wuerzburg, Wuerzburg, Germany. The approval for this study was waived by the University's ethics committee "Ethik-Komission der Universität Würzburg" on the 20th of June 2018 (approval number 20180613 01). Consent to participate was waived along with this waiver.

\section{Consent for publication}

All authors gave consent on publishing the article.

\section{Competing interests}

The authors declare that they have no competing interests.

\section{Publisher's Note}

Springer Nature remains neutral with regard to jurisdictional claims in published maps and institutional affiliations.

Received: 22 June 2018 Accepted: 22 October 2018

Published online: 10 November 2018

\section{References}

1. Choi YJ, Ra HJ. Patient satisfaction after total knee arthroplasty. Knee Surg Relat Res. 2016;28(1):1-15. https://doi.org/10.5792/ksrr.2016.28.1.1.

2. Bozic KJ, Kamath AF, Ong K, Lau E, Kurtz S, Chan V, et al. Comparative epidemiology of revision arthroplasty: failed THA poses greater clinical and economic burdens than failed TKA. Clin Orthop Relat Res. 2015;473(6):2131-8. https://doi.org/10.1007/s11999-014-4078-8.

3. EPRD Jahresbericht 2015 [database on the Internet]. Endoprothesenregister Deutschland. 2015. Accessed: 07/05/2017.

4. Schroer WC, Berend KR, Lombardi AV, Barnes CL, Bolognesi MP, Berend ME, et al. Why are total knees failing today? Etiology of total knee revision in 2010 and 2011. J Arthroplast. 2013;28(8 Suppl):116-9. https://doi.org/10. 1016/j.arth.2013.04.056.

5. Thiele K, Perka C, Matziolis G, Mayr HO, Sostheim M, Hube R. Current failure mechanisms after knee arthroplasty have changed: polyethylene wear is less common in revision surgery. J Bone Joint Surg Am. 2015;97(9):715-20. https://doi.org/10.2106/JBJS.M.01534.

6. Sadoghi P, Liebensteiner M, Agreiter M, Leithner A, Bohler N, Labek G. Revision surgery after total joint arthroplasty: a complication-based analysis using worldwide arthroplasty registers. J Arthroplast. 2013;28(8):1329-32. https://doi.org/10.1016/j.arth.2013.01.012. 
7. Tande AJ, Gomez-Urena EO, Berbari EF, Osmon DR. Management of prosthetic joint infection. Infect Dis Clin N Am. 2017;31(2):237-52. https:// doi.org/10.1016/j.idc.2017.01.009.

8. Thiele K, Fussi J, Perka C, Pfitzner T. The Berlin diagnostic algorithm for painful knee TKA. Orthopade. 2016;45(1):38-46. https://doi.org/10.1007/ s00132-015-3196-7.

9. Ahmad SS, Becker R, Chen AF, Kohl S. EKA survey: diagnosis of prosthetic knee joint infection. Knee Surg Sports Traumatol Arthrosc. 2016;24(10):3050-5. https://doi.org/10.1007/s00167-016-4303-y.

10. Chang MJ, Lim H, Lee NR, Moon YW. Diagnosis, causes and treatments of instability following total knee arthroplasty. Knee Surg Relat Res. 2014;26(2): 61-7. https://doi.org/10.5792/ksrr.2014.26.2.61.

11. De Valk EJ, Noorduyn JC, Mutsaerts EL. How to assess femoral and tibial component rotation after total knee arthroplasty with computed tomography: a systematic review. Knee Surg Sports Traumatol Arthrosc. 2016;24(11):3517-28. https://doi.org/10.1007/s00167-016-4325-5.

12. Hofmann S, Seitlinger G, Djahani O, Pietsch M. The painful knee after TKA: a diagnostic algorithm for failure analysis. Knee Surg Sports Traumatol Arthrosc. 2011;19(9):1442-52. https://doi.org/10.1007/s00167-011-1634-6.

13. Krenn V, Morawietz L, Perino G, Kienapfel H, Ascherl R, Hassenpflug GJ, et al. Revised histopathological consensus classification of joint implant related pathology. Pathol Res Pract. 2014;210(12):779-86. https://doi.org/10.1016/j. prp.2014.09.017.

14. Osmon DRBE, Berendt AR, Lew D, Zimmerli W, Steckelberg JM, Rao N, Hanssen A, Wilson WR, Infectious Diseases Society of America. Executive summary: diagnosis and management of prosthetic joint infection: clinical practice guidelines by the Infectious Diseases Society of America. Clin Infect Dis. 2013;56(1):1-10.

15. Ewald FC. The knee society total knee arthroplasty roentgenographic evaluation and scoring system. Clin Orthop Relat Res. 1989:(248):9-12.

16. Hadi M, Barlow T, Ahmed I, Dunbar M, McCulloch P, Griffin D. Does malalignment affect patient reported outcomes following total knee arthroplasty: a systematic review of the literature. Springerplus. 2016;5(1): 1201. https://doi.org/10.1186/s40064-016-2790-4.

17. Bozic K, Kurtz SM, Lau E, Ong K, Chiu V, Vail TP, et al. The epidemiology of revision total knee arthroplasty in the United States. Clin Orthop Relat Res. 2010:468(1):45-51. https://doi.org/10.1007/s1 1999-009-0945-0.

18. Suarez J, Griffin W, Springer B, Fehring T, Mason JB, Odum S. Why do revision knee arthroplasties fail? J Arthroplast. 2008;23(6 Suppl 1):99-103. https://doi.org/10.1016/j.arth.2008.04.020.

19. Mortazavi SM, Molligan J, Austin MS, Purtill JJ, Hozack WJ, Parvizi J. Failure following revision total knee arthroplasty: infection is the major cause. Int Orthop. 2011;35(8):1157-64. https://doi.org/10.1007/s00264-010-1134-1.

20. Parvizi J, Gehrke T, Chen AF. Proceedings of the international consensus on periprosthetic joint infection. Bone Joint J. 2013;95-B(11):1450-2. https://doi. org/10.1302/0301-620X.95B11.33135.

21. Fehring TK, Odum S, Griffin WL, Mason JB, Nadaud M. Early failures in total knee arthroplasty. Clin Orthop Relat Res. 2001;392:315-8.

22. Sandiford NA, Alao U, Salamut W, Weitzel S, Skinner JA. Patella resurfacing during total knee arthroplasty: have we got the issue covered? Clin Orthop Surg. 2014;6(4):373-8. https://doi.org/10.4055/cios.2014.6.4.373.

23. 14 Anual Report 2017 National Joint Registry for England, Wales, Northern Ireland and the Isle of Man [database on the Internet] 2017. Available from: http://www.njireports.org.uk/Portals/O/PDFdownloads/ NJR\%2014th\%20Annual\%20Report\%202017.pdf. Accessed: 2017/10/07.

Ready to submit your research? Choose BMC and benefit from:

- fast, convenient online submission

- thorough peer review by experienced researchers in your field

- rapid publication on acceptance

- support for research data, including large and complex data types

- gold Open Access which fosters wider collaboration and increased citations

- maximum visibility for your research: over $100 \mathrm{M}$ website views per year

At BMC, research is always in progress.

Learn more biomedcentral.com/submissions 